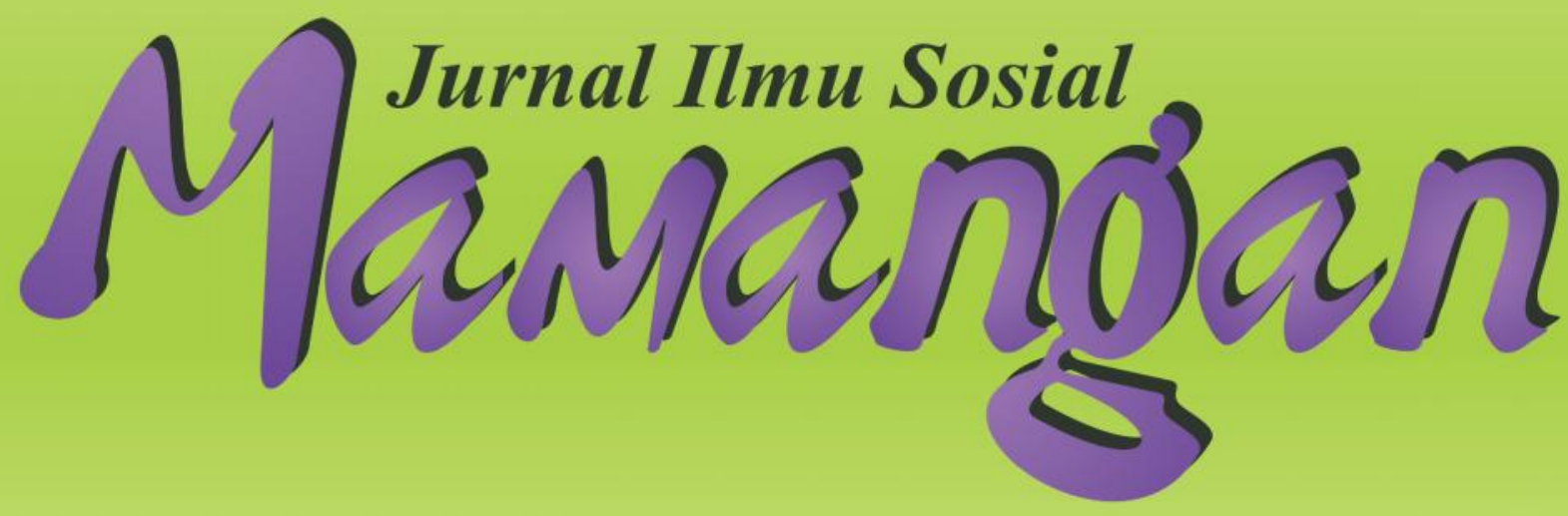

Efektifitas Program Keluarga Harapan (PKH) Dalam Upaya Pengentasan Kemiskinan Di Nagari Lagan Hilir, Kab. Pesisir selatan Apando Ekardo, Firdaus \& Nilda Elfemi

Pelaksanaan Program Corporate Social Responsibility (CSR) PT. VUM (Visi Utama Mandiri)

Yesi Herlina, Dian Anggraini Oktavia \& Elvawati

Sosial Ekonomi Perempuan Migran Kembali (Return Migrant) Jorong Kapuh, Nagari Sumani, Kab. Solok

Yuliana Nengrum, Yulkardi, Darmairal Rahmad

Pengemis Anak Di Pasar Raya Padang, Sumatera Barat

Mira Dona Eka Putri, Yulkardi \& Nilda Elfemi

Buruh Tani Jemputan Di Desa Sako Dua, Kec. Kayu Aro Barat, Kab. Kerinci

Wibi Wijaya, Zusmelia \& Elvawati

Konflik Pengelolaan Parkir Liar Di Pantai Purus, Kec. Padang Barat, Kota Padang

IImiati Amril, Ardi Abbas \& Surya Prahara 


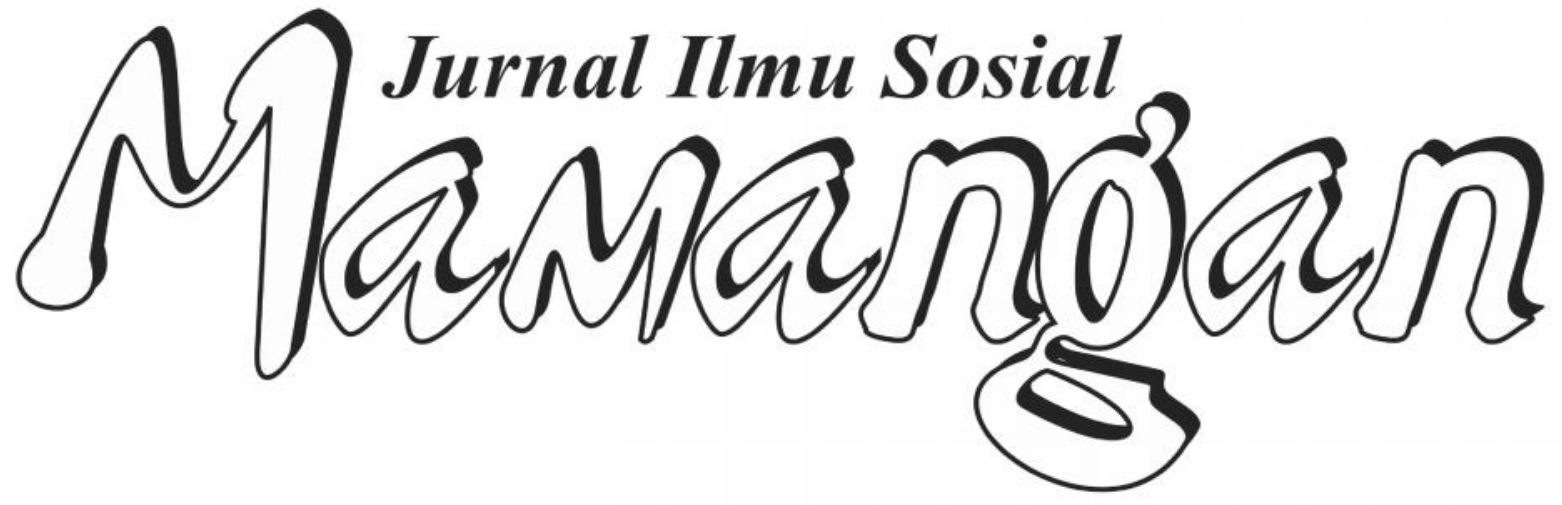




\section{Mitra Bestari}

Prof. Dr. Afrizal, MA. (FISIP, Unand Padang)

Dr. A. Latief Wiyata, M. Si. (Universitas Jember, Jember)

Prof. Dr. Badaruddin, M. Si. (FISIP, USU Medan)

Dr. Fikarwin Zuska, M. Si. (FISIP, USU Medan)

Nurus Shalihin, M. Si., Ph.D. (Fak. Ushuluddin IAIN Imam Bonjol Padang)

Dr. Semiarto A. Purwanto, M. Si. (FISIP, UI Jakarta)

Dr. Wahyu Wibowo, M. Si. (Universitas Nasional, Jakarta)

\section{Dewan Redaksi}

Dr. Zusmelia, M. Si.

Dr. Maihasni, M. Si.

Firdaus, S. Sos., M. Si.

\section{Pemimpin Redaksi}

Firdaus, S. Sos., M. Si.

\section{Anggota Redaksi}

Dian Kurnia Anggreta, S. Sos., M. Si.

Rinel Fitlayeni, S. Sos., MA.

Rio Tutri, M.Si.

Sri Rahayu, M. Pd.

Surya Prahara, SH.

Yuhelna, MA

ISSN: 2301-8496

Alamat Redaksi:

Laboratorium Program Studi Pendidikan Sosiologi, STKIP PGRI Sumbar Kampus STKIP PGRI, Jl. Gunung Pangilun, Padang, Sumatera Barat

Email: redaksimamangan@yahoo.com \& daus_gila @yahoo.com

Penerbit :

Program Studi Pendidikan Sosiologi, STKIP PGRI Padang 


\section{DAFTAR ISI}

Efektifitas Program Keluarga Harapan (PKH) Dalam Upaya Pengentasan Kemiskinan Di Nagari Lagan Hilir, Kab. Pesisir selatan

Apando Ekardo, Firdaus \& Nilda Elfemi ..

Pelaksanaan Program Corporate Social Responsibility (CSR) PT. VUM

Yesi Herlina, Dian Anggraini Oktavia \& Elvawati

Sosial Ekonomi Perempuan Migran Kembali (Return Migrant) Jorong Kapuh, Nagari Sumani, Kab. Solok

Yuliana Nengrum, Yulkardi, Darmairal Rahmad

Pengemis Anak Di Pasar Raya Padang, Sumatera Barat

Mira Dona Eka Putri, Yulkardi \& Nilda Elfemi

Buruh Tani Jemputan Di Desa Sako Dua, Kec. Kayu Aro Barat, Kab. Kerinci

Wibi Wijaya, Zusmelia \& Elvawati.

Konflik Pengelolaan Parkir Liar Di Pantai Purus, Kec. Padang Barat, Kota Padang

Ilmiati Amril, Ardi Abbas \& Surya Prahara

$40-48$ 


\title{
SOSIAL EKONOMI PEREMPUAN MIGRAN KEMBALI (RETURN MIGRANT) JORONG KAPUH, NAGARI SUMANI, KAB. SOLOK
}

\author{
Yuliana Nengrum 1 , Yulkardi'2, Darmairal Rahmad ${ }^{3}$ \\ 1 \& 3 Sekolah Tinggi Keguruan dan Ilmu Pendidikan (STKIP) PGRI Sumatera Barat \\ 2 Sosiologi, Universitas Andalas
}

\begin{abstract}
Marantau is a tradition in Minangkabaunes. Such as with Jorong Kapuh society it is economic factor and behavior as support their to do it. In the bight economic factor homogeny and less economic to get daily want until $70 \%$ in that condition. The aims based on resolution of the problem are: first, to describe a woman knowledge about bight, second, to describe the reason a woman can do it, third, to describe the reason a woman as a brighter and return migrant, fourth, to describe economic social condition us return migrant. Research counducted with qualitative approach with descriptive method. Informant chosed using purposive. The result of this research conclusion of bight woman is studied, couple research, socialization with another society. Social economic condition have two differences variable, first, economic variable (their physic necessity, health for economic physic), second, social variable (long life need, the appreciate of society, help another, success in their life).
\end{abstract}

Keyword : Socio Economic, Marantau, Return Migrant

\begin{abstract}
ABSTRAK
Merantau merupakan tradisi masyarakat Minangkabau. Demikian halnya dengan masyarakat Jorong Kapuh, selain dari merantau menjadi suatu tradisi faktor ekonomi dan keadaan alam juga sebagai pendorong bagi masyarakat Jorong Kapuh untuk merantau. Berdasarkan rumusan masalah terdapat empat tujuan penelitian yaitu: pertama, mendeskripsikan pengetahuan perempuan tentang merantau, kedua, mendeskripsikan alasan perempuan merantau, ketiga, mendeskripsikan alasan perempuanperantau, kembali kekampunghalamannya, keempat, mendeskripsikan kondisi sosiale konomi perempuan perantau pasca migrasi sebagai migrant kembali. Penelitian dilakukan dengan pendekatan kualitatif dengan metode penelitian deskriptif. Teknik pengambilan informan dilakukan dengancara purposive sampling. Hasil dari penelitian ini, dapat disimpulkan bahwa perempuan merantau yaitu mencari pengalaman hidup, perubahan ekonomi yang lebih baik, mencari jodoh, menuntut ilmu, bersosialisasi dengan masyarakat di rantau. Kondisi sosial ekonomi perempuan perantau migrant kembali dibedakan dua yaitu: pertama, ekonomi (berupa kebutuhan dasar berupa sandang, pangan, papan, kesehatan, terpenuhinya kebutuhan ekonomi). Kedua, secara sosial (berupa terpenuhinya kebutuhan hidup, saling bekerjasama, penghargaan yang di berikan oleh masyarakat, keberhasilan perubahan hidup yang dicapai)
\end{abstract}

Kata Kunci : Sosial Ekonomi, Marantau, Migran kembali 


\section{PENDAHULUAN}

Jorong Kapuh Nagari Sumani Kecamatan X Koto Singkarak Kabupaten Solok sebagian besar dari masyarakat hidup di rantau, perantauan yang dilakukan lebih mengacu kepada migrasi sementara karena migrasi sementara merupakan suatu migrasi yang pergi merantau dengan jangka waktu beberapa tahun dan bertujuan kembali lagi ke kampung halamannya, hal ini dilakukan oleh masyarakat Jorong Kapuh salah satunya yang melakukan perantauan adalah perempuan. Pada umumnya perempuan hanya berada dirumah sebagai ibu rumah tangga dan menjalankan fungsi pengasuhan anak, tetapi hal ini sudah mengalami perobahan dengan seiring perkembangan zaman, semestinya perantau dilakukan oleh laki-laki karena kondisi sosial ekonomi yang membuat ia tidak bisa menutup mata bahwa kadang-kadang dalam memenuhi kebetuhan hidup perempuan dituntut untuk harus pergi merantau agar kebutuhan ekonominya terpenuhi. Perempuan perantau banyak tersebar diberbagai daerah, tidak hanya di Sumatera Barat tetapi juga terdapat di Pulau Jawa, hal ini juga disebabkan karena perempuan berada diberbagai penjuru dunia.

Semakin bertambahnya anggota keluarga maka sebagian kecil yang mendapatkan pembagian harta berupa rumah gadang, tanah, ladang, dan sawah. Rumah gadang sebagai tempat berteduhya keluarga bersama sekarang rumah gadang yang sama itu terpaksa dibagi dua dengan saudara perempuan lain, karena yang sebelah hendak membangun rumah baru diatas tanah rumah gadang, sedangkan keluarga saudara perempuan lain masih menempati rumah gadang sebagai tempat berteduh mereka.

Lebih sulit halnya sampai kepada masalah ladang dan sawah pusaka. Sejak usaha di kampung, persawahan telah tersesak ke lembah, ngarai dan gununggunung, terjadi bahwa kebutuhan yang sama harus dibagi kepada jumlah jiwa yang makin lama makin banyak dan lebih dipersulit lagi oleh ketentuan adat bahwa harta pusaka tidak boleh dibeli atau dijual. Keadaan ekonomi di Jorong Kapuh tidak mencukupi kebutuhan hidup perempuan maka mereka menggadaikan sawah dan ladang yang dipunya untuk tetap bertahan hidup, dalam hal itu baru bisa dilakukan jika tidak ada lagi jalan lain untuk menutupinya dan jika semua anggota keluarga sependapat. Hal ini juga yang membuat perempuan di Jorong Kapuh untuk mengikuti suami pergi merantau, karena harta di daerah asal banyak yang tergadai, dengan tujuan kembali pulang untuk membangun rumah, mengambil sawah dan ladang yang tergadai.

Perempuan perantau di Jorong Kapuh pada awalnya sangat berpengaruh terhadap kondisi sosial dan ekonomi masyarakatnya. Pada awalnya merantau dilakukan perempuan karena ikut suami kerantau demi memenuhi kebutuhan hidup dan kita ketahui juga bahwa masyarakat Minangkabau menganut sistem matrilineal yaitu menurut garis keturunan ibu. Saudara perempuan ini memiliki hak dalam kepemilikan harta pusaka berupa, tanah, rumah gadang, ladang dan sawah

Perempuan perantau di Nagari Sumani berasal dari dua belas Jorong, adapun paling dominan yang melakukan perantauan dan perantau pulang ke daerah asal terdapat pada Jorong Kapuh. Peneliti ingin melihat tentang perempuan Nagari Sumani yang pulang dari perantauan pada tahun 2013 berjumlah 1.410 orang perantau, namun berdasarkan hasil data diatas Jorong yang banyak melakuan pulang ke daerah asal terdapat pada Jorong Kapuh sebanyak 182 orang. Selama di perantauan perempuan bekerja dan mendapatkan penghasilan yang beragam, sesuai dengan usaha dan kegigihannya di rantau.

Sebagian besar perempuan Nagari Sumani yang merantau dapat dikatakan ada yang sukses dan tidak sukses. Hal tersebut dapat dilihat dari beberapa indikator, bagi yang sudah sukses di perantauan, mereka sudah memiliki kendaraan pribadi, sudah mampu untuk menunaikan ibadah haji, sudah memiliki usaha yang semakin maju seperti tidak hanya berdagang saja tetapi ada yang sudah mempunyai rumah untuk disewakan, selain itu bertujuan pulang untuk membangun rumah terutama rumah untuk anak perempuan mereka agar keberadaannya dihargai orang kampung, ladang dan sawah yang tergadai akan diambil kembali.

Perempuan yang tidak sukses di rantau ia juga kembali pulang ke daerah 
asalnya, dengan tujuan berusaha untuk berdagang dan membuat usaha lain dengan pengalaman yang didapatnya selama pergi meratau, dengan bekal dan pengalaman yang didapat di perantauan bisa mencari kehidupan lain dengan cara mencari kehidupan membuat usaha seperti berdagang, untuk dapat dihargai orang kampung yang bertujuan memperbaiki ekonominya dan dapat merubah hidup. Berdasarkan latar belakang di atas, tujuan dari Penelitian ini adalah: Mendeskripsikan kondisi sosial ekonomi perempuan perantau sebagai migran kembali di Jorong Kapuh Nagari Sumani Kecamatan X Koto Singkarak Kabupaten Solok

\section{TINJAUAN PUSTAKA}

Perantau berarti orang yang melakukan migrasi, tetapi merantau adalah khusus dari migrasi dengan konotasi budaya tersendiri. Merantau adalah istilah Melayu, Indonesia dan Minangkabau yang sama artinya dengan pemakaian kata dasar "rantau". Merantau adalah suatu kata dasar yang berawalan "me" yang berarti pergi ke rantau atau daerah diluar kampung halamannya. Perantau adalah orang yang meninggalkan kampung halamannya untuk melakukan aktivitas sosial ekonomi.Istilah merantau (orang yang melakukan kegiatan merantau) ini sangat dikenal dan lazim digunakan oleh masyarakat Minangkabau. Tradisi merantau orang Minangkabau telah melembaga dalam kosmologi adat Minangkabau dan telah berlangsung beratus tahun yang lalu (Naim, 2013)

Tujuan merantau sering dikaitkan dengan tiga hal: mencari harta (berdagang atau menjadisaudagar), mencari ilmu (belajar), atau mencari pangkat (pekerjaan atau jabatan). Merantau juga merupakan, proses interaksi masyarakat Minangkabau dengan dunia luar. Kegiatan ini, menjadikan sebuah pertualangan pengalaman dan geografis, dengan meninggalkan kampung halaman untuk mengadu nasib di nagari orang. Berbeda dengan proses transmigrasi yang diprogramkan serta dibiayai pemerintah. Orang Minangkabau merantau dengan kemauan dan kemampuannya sendiri. Perantau merupakan, orang yang pergi meninggalkan kampung halamannya atau daerah asalnya kedaerah lain untuk mencari ilmu dan mengadu nasib, dengan cara berdagang dan usaha lainnya tetapi tidak lupa akan kampung halamannya. Mereka melihat proses ini semacam penjelajahan, hijrah, untuk membangun kehidupan yang lebih baik (Sjarifoedin, 2011).

Menurut (Naim, 2013) yang membahas tentang merantau pola migrasi suku Minangkabau. Pembahasan dalam buku itu menjelaskan tentang adanya kata kerja barawalan "me" yang berarti "pergi ke rantau", tetapi dari sudut sosiologi megandung enam unsur pokok berikut:

1. Meninggalkan kampung halaman

2. Dengan kemauan sendiri

3. Untuk jangka waktu lama atau tidak

4. Dengan tujuan mencari penghidupan, menuntut ilmu atau mencari pengalaman

5. Biasanya dengan maksud kembali pulang dan

6. Merantau ialah lembaga sosial yang membudaya

Jadi perantau adalah orang yang pergi meninggalkan kampung halamannya atau daerah asalnya kedaerah lain untuk mencari ilmu dan mengadu nasib, dengan cara berdagang dan usaha lainnya tetapi tidak lupa akan kampung halamannya.

\section{MIGRAN KEMBALI (RETURN MIGRANT)}

Migran kembali (return migrant) adalah migrasi orang-orang yang kembali ke daerah asalnya, yaitu setelah daerah asal (out-migration) pertama mereka (Susetyo, 1994). Migran kembali merupakan kembalinya migrasi ke rumah atau negara asal salah satu cara orang untuk berhenti menjadi migran meskipun sering kali setelah mereka kembali kerumah orang memelihara unsur praktek-praktek baru dan mereka yang telah mengembangkan indentitas luar negeri (Sarah, 2012). Migrasi sementara diartikan juga sebagai migran kembali yaitu merupakan suatu migrasi yang pergi merantau dengan jangka waktu beberapa tahun dan bertujuan kembali lagi kekampung halamannya (Naim, 2013).Jadi pengertian migrasi adalah kejadian yang penting tidak hanya bagi beberapa orang tetapi juga bagi komunitas-komunitas. Migrasi dari suatu arealainnya mempunyai dampak berkurangnya populasi didaerah 
asal dan menambah ukuran populasi di daerah tujuan.

\section{METODE PENELITIAN}

Penelitian ini menggunakan pendekatan kualitataif yang berusaha mengungkapkan dan memahami realitas yang ada di lapangan sesuai dengan kondisi real di lapangan. Tipe penelitian ini adalah deskriptif, yang menggambarkan secara mendalam, faktual dan akurat tentang latar pengamatan, tindakan dan pembicaraan. Pengambilan informan dilakukan dengan cara purposive sampling dengan jumlah informan 20 orang, dengan kriteria informan perempuan perantau yang pulang ke kampung dan tidak ada niat untuk kembali merantau, perempuan yang pernah merantau \pm 5 tahun dan sekarang dalam posisi sebagai migran kembali. Jenis data yang digunakan yaitu data primer dan data sekunder. Teknik pengumpulan data penelitian ini adalah observasi, wawancara, triangulasi, dan penelusuran dokumen.

\section{KONDISI SOSIAL EKONOMI PEREMPUAN PERANTAU MIGRAN}

Pengetahuan perempua tentang merantau juga merupakan gejala yang ditemui dan diperoleh manusia melalui pengamatan akal. Pengamatan muncul ketika seseorang menggunakan akal budinya untuk mengenali benda atau kejadian tertentu yang belum pernah dilihat atau dirasakan sebelumnya. Pengetahuan dalam penelitian ini dapat dilihat dari upaya perempuan untuk merubah hidup atau nasib, merubah harga diri agar lebih dipandang dilingkungan masyarakat tempat perempuan migran kembali berada, pergi merantau untuk mencari modal, menembus sawah atau ladang yang tergadai di kampung, dan melanjutkan studi yang lebih baik.

Pengetahuan yang didapat oleh perempuan migran kembali memiliki nilai yang terkandung dibalik perempuan merantau, nilai itu diperoleh dari orang tua dan sanak saudara (mamak, uda, etek dan nenek atau kakek). Nilai itu dapat dibedakan atas dua bagian, Pertama nilai positif $(+)$ mempercayai seorang anak untuk pergi merantau agar dapat merubah kehidupan keluarga, memberikan modal ilmu agama, mengingatkan kepada anak agar berhati-hati dengan pergaulan di rantau dan mencari pekerjaan di rantau agar dapat membantu biaya hidup keluarga yang berada di kampung. Kedua nilai negatif (-) tidak ada sanak saudara di rantau, melanjutkan studi yang tidak sempat ditamatkan dan kekhawatiran akan anak perempuan satu-satunya di rumah atau kekhawatiran untuk melepaskan anak perempuan pergi meratau.

1. Alasan perempuan pergi merantau (motivasi merantau) banyak ragamnya mulai dari keinginan individu untuk melanjutkan pendidikan atau studi, tidak bisa membantu orang tua karena orang tua sudah meninggal, masalah pembagian harta warisan yang tidak merata kepada sanak saudara, sawah atau ladang yang tergadai karena biaya hidup dan sekolah, biaya kotrakan rumah yang semakin mahal, mencari pekerjaan lain selain bertani dan usaha yang dimiliki di kampung jatuh bangkrut.

2. Perempuan merantau kembali ke kampung karena mata pencarian sebagai pedagang tidak membuahkan hasil (bangkrut atau kena gusur), pendapatan yang diterima tidak bisa mencukupi kebutuhan hidup, biaya hidup di rantau sangat besar, sudah menamatkan studi selama di rantau, berkeinginan untuk mencari pekerjaan di kampung, sudah pensiun, membuka usaha, keadaan orang tua yang tidak kuat lagi untuk bekerja atau tidak ada yang mengurusnya, ikut pindah tugas kerja bersama suami di kampung, biaya kontrakan rumah yang mahal, menjemput sawah atau ladang yang tergadai dan membangun rumah di kampung.

3. Kondisi sosial ekonomi perempuan perantau pasca migran sebagai migran kembali dapat dilihat dari kondisi ekonomi (bersifat fisik) merupakan suatu keadaan yang berkaitan dengan prilaku nyata individu atau yang berhubungan dengan proses sosial yang menyangkut masalah pola aktivitas manusia dalam produksi, distribusi dan konsumsi. Dapat dilihat dari (a). variabel fisiologi mengenai perempuan perantau, dilihat dari kondisi ekonominya hanya sebagian perempuan 
yang bisa memenuhi kebutuhan dasarnya dan ada juga perempuan yang tidak bisa memenuhi kebutuhan dasarnya berupa sandang, pangan, papan dan kesehatan bertujuan untuk melangsungkan kebutuhan hidup, (b). variabel rasa aman dan perlindungan mengenai kondisi ekonomi, belum terpenuhinya kebutuhan ekonomi membuat perempuan tidak bisa membangun rumah, menjemput sawah atau ladang yang tergadai dan selalu berhutang kepada tetangga.

Kondisi sosial (bersifat non fisik) merupakan suatu keadaan atau situasi individu dalam melakukan tindakan dan interaksi dengan lingkugan dalam rangka pemenuhan kebutuhan hidup serta mengangkat harkat dan martabat seseorang. Dilihat dari a). variabel rasa aman dan perlindungan menyangkut tentang perasaan bebas dari rasa takut, kemiskinan dan kelaparan. Hal ini dilakukan perempuan perantau migran kembali agar terhindar dari rasa takut akan kelaparan, kemiskinan dan menghindari adanya hutang yang menumpuk agar kebutuhan hidup mereka bisa tetap terpenuhi.

b). variabel sosial merupakan kebutuhan akan diakui sebagai anggota kelompok, kerja sama, persahabatan dan interaksi. Keadaan ini terjadi ketika perempuan migran kembali berada pada keadaan bangkrut. Hal ini juga disebabkan oleh saudaranya sendiri yang tidak mau saling bekerja sama dan adanya rasa membutuhkan ketika mengadakan acara ta'jiah, yasinan dan wirit terjalinnya suatu interaksi. c). variabel penghargaan meliputi tentang kebutuhan yang menghargai kemampuan orang lain, jabatan, dan status.

Hal ini terkait dengan perempuan yang memiliki kemampuan untuk membuka usaha bertujuan agar terpenuhinya kebutuhan hidup dan memiliki status sebagai bidan bertujuan untuk menolong masyarakat yang sedang membutuhkannya. d). variabel aktualisasi diri berupa kemampuan, kreativitas, dan memiliki perestasi. Perempuan perantau migran kembali yang memiliki kemampuan akan kreatifitas dalam bekerja dan berkeingin untuk dihargai keberadannya di kampung. Semua hal yang perempuan lakukan ini bempengaruh kepada penghasilan yang mereka dapatkan dan juga bertujuan untuk terpenuhinya kebutuhan hidup mereka.

\section{KESIMPULAN}

Perempuan merupakan salah satu aktor atau pelaku merantau di Jorong Kapuh Nagari Sumani Kecamatan X Koto Singkarak Kabupaten Solok, hal ini disebabkan oleh pengetahuan perempuan tentang pergi merantau dapat merubah nasib, baik merantau untuk melanjutkan pendidikan maupaun dengan usaha lainnya, sehingga bisa merobah nasib dari kondisi ekonomi yang tidak layak, menjadi lebih layak. Pada umunya perantau ini kembali ke kampung halamannya sehingga mereka disebut juga dengan migrant kembali atau return migration. Hasil penelitian ini mendunjukkan bahwa kondisi migrant kembali dapat diilihat dari kondisi sosial dan ekonominya. Secara ekonomi, sebagian perempuan yang merantau telah bisa memenuhi kebutuhan dasarnya dan berupa sandang, pangan, papan dan kesehatan yang bertujuan untuk melangsungkan kebutuhan hidup. Selain itu dari kondisi sosial perempuan yang bersifat non fisik, merupakan kebutuhan akan rasa aman atau perlindungan, sosial, penghargaan dan kebutuhan akan aktualisasi diri yang dibutuhkan untuk menjalin hubungan interaksi dengan lingkungan masyarakat dalam rangka pemenuhan kebutuhan hidup. Perempuan yang pulang dari merantau atau migrant kembali telah mampu merubah harga dirinya, menjadai lebih dipandang dilingkungan masyarakat tempat perempuan migran kembali berada, karena dari penghasilan yang didapat selama di rantau membuat mereka mampu menembus sawah atau ladang yang tergadai di kampung.

\section{DAFTAR PUSTAKA}

Naim, M. (2013). Merantau Pola Migrasi Suku Minangkabau Edisi Ketiga.

Sarah, aira. (2012). Migrasi Internasional. Jurnal Mahasiswa HI Fisip UR, 2(2), 18.

Sjarifoedin, T. A. A. (2011). Minangkabau 
Dari Dinasti Iskandar Zulkarnain

Sampai Tuanku Iman Bonjol.

Susetyo, I. B. (1994). Pembekalan

Musrembang Kabupaten Malang. Jurnal
Mahasiswa Program Studi Perencanaan Pembangunan, Administrasi Publik, FIA, Universitas Brawija. 


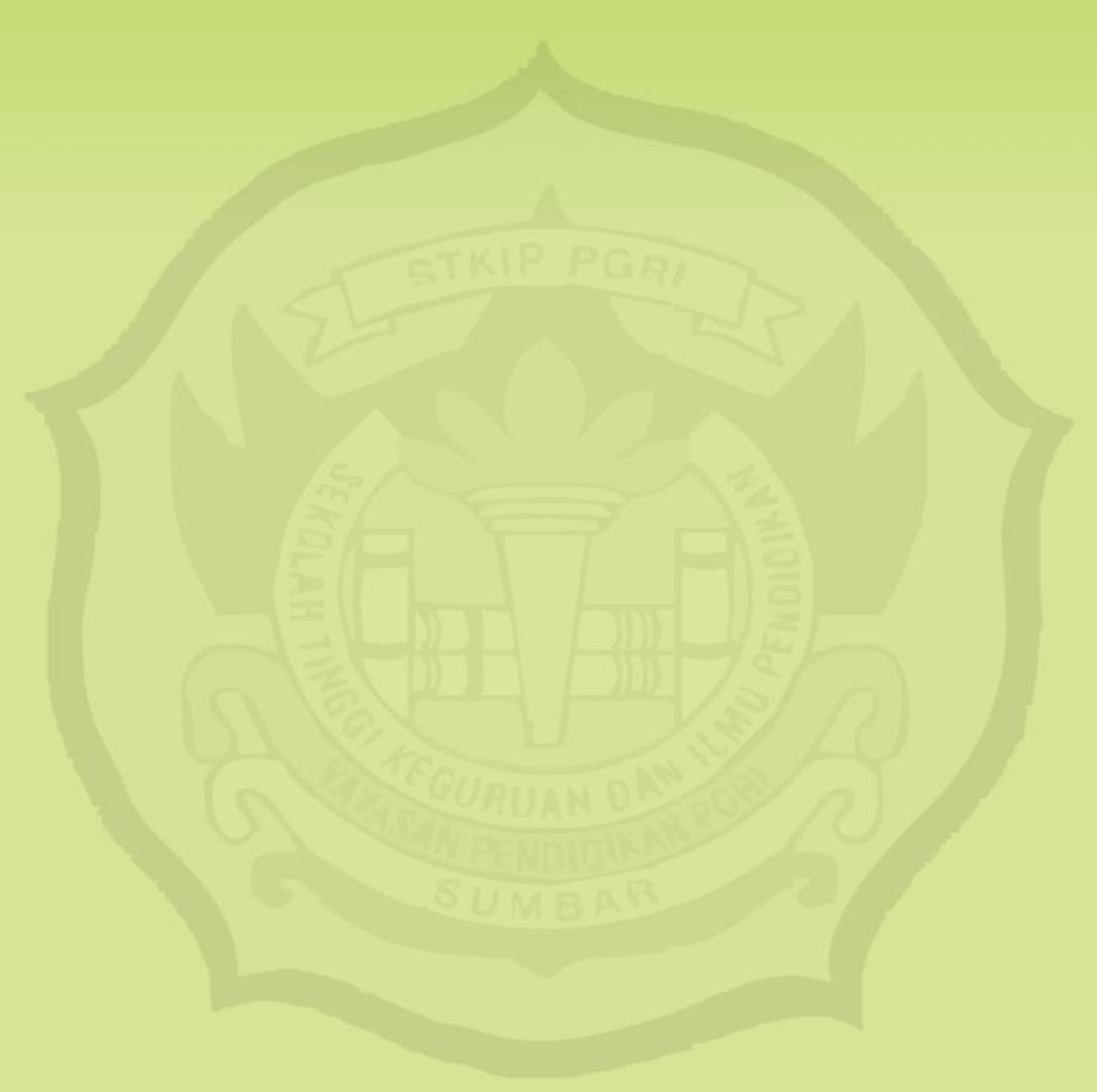

